\title{
PERANCANGAN DAN IMPLEMENTASI APLIKASI SISTEM PAKAR UNTUK DIAGNOSA GANGGUAN KEHAMILAN MENGGUNAKAN METODE BAYES
}

\author{
Leva Affrillianggi Falihah ${ }^{1}$, Slamet Santoso ${ }^{2}$, Silvia Elrahman ${ }^{3}$ \\ 1,3 Jurusan Sistem Informasi Konsentrasi Komputer Akuntansi STT Indonesia Tanjungpinang \\ Jln. Pompa Air No. 28 Tanjungpinang Kepulauan Riau Indonesia \\ ${ }^{1}$ leva_falihah05@yahoo.com \\ 22slamet_santoso@sttindonesia.ac.id \\ ${ }^{3}$ silviaelrahman@gmail.com
}

\begin{abstract}
Intisari- Pada masa Kehamilan, ibu hamil pada umumnya mengalami berbagai macam gangguan kehamilan baik yang bersifat ringan maupun yang bersifat berat. Untuk mendiagnosa masalah tersebut idealnya diperlukan konsultasi kepada ahlinya, dalam hal ini bidan atau dokter spesialis kandungan (spesialis obstetri dan ginekologi) sehingga pemberian solusi lebih akurat dan efektif. Dengan kemajuan teknologi komputer yang pesat seperti sekarang ini banyak membantu manusia dalam berbagai bidang kehidupan, salah satunya adalah bidang kesehatan. Salah satu teknologi komputer yang digunakan adalah Artificial Intelligence (kecerdasan buatan). Kecerdasan buatan dapat membuat komputer lebih mudah digunakan dengan tampilan yang menggunakan bahasa yang natural sehingga mudah dipahami, dan salah satu bagian dari sistem kecerdasan buatan adalah sistem pakar. Sistem Pakar adalah sistem berbasis komputer yang menggunakan pengetahuan, fakta dan teknik penalaran dalam memecahkan masalah yang biasanya hanya dapat dipecahkan oleh seorang pakar dalam bidang tersebut. Dengan demikian maka sistem pakar pun dapat digunakan untuk membantu dalam mendiagnosa gangguan pada kehamilan.
\end{abstract}

Kata Kunci : Sistem Pakar, Diagnosa, Kehamilan.

Abstract - During pregnancy, pregnant women generally experience various kinds of pregnancy disorders, both mild and severe. To diagnose this problem, ideally it requires consultation with an expert, in this case a midwife or obstetrician (obstetrician and gynecologist) so that the provision of solutions is more accurate and effective. With the rapid advancement of computer technology as it is now helping people in various fields of life, one of which is the health sector. One of the computer technologies used is Artificial Intelligence. Artificial intelligence can make computers easier to use with displays that use natural language so that they are easy to understand, and one part of an artificial intelligence system is an expert system. Expert Systems are computer-based systems that use knowledge, facts and reasoning techniques to solve problems that normally only an expert in the field can solve. Thus, an expert system can also be used to assist in diagnosing disorders of pregnancy.

Keywords - Expert System, Diagnosis, Pregnancy.

\section{Pendahuluan}

Kehamilan merupakan fungsi normal dari tubuh dan bagian dari fase kehidupan wanita, dimana pada tahap tersebut terdapat kehidupan baru dalam tubuh seorang ibu berupa janin yang akan tumbuh menjadi bayi. Pada masa inilah, ibu hamil pada umumnya mengalami berbagai macam gangguan kehamilan baik yang bersifat ringan maupun yang bersifat berat. Untuk mendiagnosa masalah tersebut idealnya diperlukan konsultasi kepada ahlinya, dalam hal ini bidan atau dokter spesialis kandungan (spesialis obstetri dan ginekologi) sehingga pemberian solusi lebih akurat dan efektif.

Permasalahan muncul apabila terdapat hambatan untuk konsultasi, baik keterbatasan waktu, kondisi fisik yang tidak memungkinkan untuk meninggalkan rumah, maupun masalah finansial sehingga menghambat proses penyelesaian masalah.

Untuk mengatasi hambatan tersebut, sebuah sistem representasi pengetahuan yang diaplikasikan dalam bentuk program aplikasi berbasis dekstop mencoba menawarkan solusi pemecahannya dengan layanan konsultasi yang dapat dilakukan kapan saja dan dimana saja, sehingga tidak terbatas ruang dan waktu.

Dengan kemajuan teknologi komputer yang pesat seperti sekarang ini banyak membantu manusia dalam berbagai bidang kehidupan, salah satunya adalah bidang kesehatan. Saat ini sudah banyak bidang kesehatan yang menggunakan teknologi komputer untuk membantu menyelesaikan permasalahan yang terjadi seperti melakukan operasi, medical check up dan lain-lain. Salah satu teknologi komputer yang digunakan adalah Artificial Intelligence (kecerdasan buatan). Sistem Pakar adalah sistem berbasis komputer yang menggunakan pengetahuan, fakta dan teknik penalaran dalam memecahkan masalah yang biasanya hanya dapat dipecahkan oleh seorang pakar dalam bidang tersebut Dalam perkembangannya, sistem pakar banyak membantu manusia dalam berbagai bidang, antara lain dalam bidang kesehatan. Dengan demikian maka sistem pakar pun dapat digunakan untuk membantu dalam mendiagnosa gangguan pada kehamilan. 


\section{Metodologi Penelitian}

Merupakan suatu teknik atau cara untuk menggumpulkan data atau fakta yang nantinya akan dipelajarai dan digunakan sebagai bahan untuk memudshksn pencarian pemecahan masalah.

A. Metode Pengumpulan Data

Metode yang digunakan untuk mendapatkan data yang diperlukan sebagai berikut :

\section{1) Interview}

Penulis melakukan wawancara langsung pada sang pakar untuk memperoleh penjelasan yang tepat dan akurat sehingga penulis dapat mencatat hal-hal penting dan perlu dijadikan sebagai bahan dalam penulisan skripsi.

2) Studi Pustaka

Penulis mencari bahan-bahan atau materi sumber yang dapat di gunakan sebagai referensi penulis atau mencari hal-hal yang dapat digunakan dalam membuat Sistem Pakar Untuk Mendeteksi Gangguan Pada Masa Kehamilan Menggunakan Metode Bayes.

B. Metode Pengembangan Perangkat Lunak

Metode pengembangan perangkat lunak pada pembuatan prototipe ini adalah menggunakan model Waterfall. Metode Waterfall ini memudahkan penulis dalam melakukan penelitian karena lebih terstruktur, dinamis dan sekuensial. Metode pengerjaan dari suatu sistem dilakukan secara berurutan atau secara linear. Jadi jika langkah satu belum dikerjakan maka tidak akan bias melakukan pengerjaan langkah, 2, 3 dan seterusnya. Secara otomatis tahapan ke-3 akan bisa dilakuan jika tahap ke-1 dan ke-2 sudah dilakuan.

Secara garis besar metode waterfall mempunyai langkahlangkah sebagai berikut:

1) Analisa

Langkah ini merupakan analisa terhadap kebutuhan sistem. Pengumpulan data dalam tahap ini bisa melakukan sebuah penelitian, wawancara atau study literature. Tahapan ini akan menghasilkan dokumen user requirment atau bisa dikatakan sebagai data yang berhubungan dengan keinginan user dalam pembuatan sistem. Dokumen ini lah yang akan menjadi acuan sistem analis untuk menterjemahkan ke dalam bahasa pemprogram.

\section{2) Design}

Proses desain akan menerjemahkan syarat kebutuhan ke sebuah perancangan perangkat lunak yang dapat diperkirakan sebelum dibuat coding. Proses ini berfokus pada: struktur data, arsitektur perangkat lunak, representasi interface, dan detail (algoritma) prosedural. Tahapan ini akan menghasilkan dokumen yang disebut software requirment. Dokumen inilah yang akan digunakan programmer untuk melakukan aktivitas pembuatan sistemnya.

3) Coding dan Testing Coding

Merupakan penerjemahan design dalam bahasa yang bisa dikenali oleh komputer. Dilakukan oleh programmer yang akan meterjemahkan transaksi yang diminta oleh user. Tahapan ini lah yang merupakan tahapan secara nyata dalam mengerjakan suatu sistem. Dalam artian penggunaan komputer akan dimaksimalkan dalam tahapan ini. Setelah pengkodean selesai maka akan dilakukan testing terhadap sistem yang telah dibuat tadi. Tujuan testing adalah menemukan kesalahan-kesalahan terhadap sistem tersebut dan kemudian bisa diperbaiki.

4) Penerapan

Tahapan ini bisa dikatakan final dalam pembuatan sebuah sistem. Setelah melakukan analisa, design dan pengkodean maka sistem yang sudah jadi akan digunakan oleh user.

5) Pemeliharaan

Pemeliharaan merupakan tahapan untuk melakukan perbaikan atau pun penambahan kebutuhan lain diluar hasil perancangan dan implementasi yang dapat meningkatkan kinerja dari sistem yang telah terbentuk.

\section{Hasil dan Pembahasan}

A. Perhitungan Dengan Teorema Bayes

Berikut ini tahapan perhitungan dengan menggunakan teorema bayes berdasarkan studi kasus yang penulis ambil. Adapun studi kasus yang penulis ambil adalah studi kasus tentang diangnosa gangguan kehamilan pada ibu hamil yang ditandai dengan gejala-gejala yang tampak atau dirasakan oleh ibu hamil.

1) Membuat Tabel Data Gangguan Kehamilan

Sebelum membuat tabel data gangguan maka kita perlu untuk menentapkan range nilai kepercayaan berdasarkan pengalaman dari seorang pakar terhadap kejadian yang telah terjadi. Berikut ini adalah tabel range nilai kepercayaan:

Tabel 1: Range Nilai Kepercayaan
\begin{tabular}{|l|l|}
\hline Range Nilai Kepercayaan \\
\hline Skor $<40 \%$ & Tidak \\
\hline Skor $40-55 \%$ & Mungkin \\
\hline Skor $56-75 \%$ & Hampir Pasti \\
\hline Skor $>76 \%$ & Pasti \\
\hline
\end{tabular}

Tabel gangguan digunakan sebagai pola pencocokan informasi yang dimasukkan oleh pemakai dan basis pengetahuan.

Tabel 2 : Gangguan Kehamilan

\begin{tabular}{|l|l|c|}
\hline $\begin{array}{c}\text { Kode } \\
\text { Gangguan }\end{array}$ & \multicolumn{1}{|c|}{ Nama Gangguan } & $\begin{array}{c}\text { Bobot (Probabilitas } \\
\text { Kejadian Penyakit } \\
\text { Tanpa Melihat } \\
\text { Gejala) }\end{array}$ \\
\hline GA-001 & Morning Sickness & 0,9 \\
\hline GA-002 & Stretch Mark & 0,9 \\
\hline GA-003 & Anemia & 0,9 \\
\hline GA-004 & Hipertensi & 0,8 \\
\hline GA-005 & Diabetes Melitus Gestasional & 0,8 \\
\hline GA-006 & Oedema & 0,8 \\
\hline GA-007 & Ambeien & 0,7 \\
\hline GA-008 & Dispepsia & 0,7 \\
\hline GA-009 & Infeksi Saluran Kemih & 0,6 \\
\hline GA-010 & Campak & 0,6 \\
\hline
\end{tabular}

2) Membuat Tabel Data Gejala 
Tabel gejala gangguan digunakan sebagai pola pencocokan informasi yang dimasukkan oleh pemakai dan basis pengetahuan.

\begin{tabular}{|c|c|}
\hline Kode Gejala & Nama_Gejala \\
\hline GE-001 & Mual dan muntah \\
\hline GE-002 & Mual pada pagi hari \\
\hline GE-003 & Mudah merasa lelah \\
\hline GE-004 & Terdapat guratan kulit di paha,pinggul,bokong dan payudara \\
\hline GE-005 & Rasa gatal di perut disertai kemerahan di kulit perut, payudara \\
\hline GE-006 & Permukaan kulit, bibir dan wajah pucat \\
\hline GE-007 & Gampang lelah, lesu dan sesak \\
\hline GE-009 & Pandangan Kabur \\
\hline GE-010 & Nyeri pada tengkuk \\
\hline GE-011 & Kaki bengkak dan sakit kepala \\
\hline GE-012 & Rasa lapar dan haus yang berlebihan \\
\hline GE-013 & Sering buang air kecil \\
\hline GE-014 & Sering mengalami infeksi disaat sedang mengalami luka kulit \\
\hline GE-015 & Nyeri sekitar panggul dan perut kanan/kiri \\
\hline GE-016 & $\begin{array}{l}\text { Penurunan berat badan meskipun nafou makan mengalami } \\
\text { peningkatan }\end{array}$ \\
\hline GE-017 & Pembengkakan dan pegal pada kaki \\
\hline GE-018 & Pembengkakan jari tangan \\
\hline GE-019 & Pembengkakan pada wajah ibu hamil \\
\hline GE-020 & Susah buang air besar \\
\hline GE-021 & Timbul benjolan kecil di dubur \\
\hline GE-022 & Buang air besar disertai darah \\
\hline GE-023 & Rasa nyeri seperti panas di ulu hati sampai ke tenggorokan \\
\hline GE-024 & Nyeri pada lambung disertai mual dan muntah \\
\hline GE-025 & Kembung digertai parasaan kenyang \\
\hline GE-026 & Rasa perih seperti terbakar di perut bagian atas \\
\hline GE-027 & Mata kemerahan dan jadi sensitive terhadap cahaya \\
\hline GE-028 & $\begin{array}{l}\text { Pada lapisan mukosa pipi sebelah dalam akan tampak ada } \\
\text { bercak }\end{array}$ \\
\hline GE-029 & Sering merasakan ingin buang air kecil tetapi tidak keluar \\
\hline GE-030 & Terasa nyeri atau terbakar di kandung kemih \\
\hline GE-031 & Tidak bisa buang air kecil akibatnya timbul demam \\
\hline
\end{tabular}

3) Membuat Tabel Basis Aturan (Probabilitas Kejadian Gangguan Karena Suatu Gejala.

Tabel 4: Basis Aturan

\begin{tabular}{|l|c|c|c|c|c|c|c|c|c|c|}
\hline \multicolumn{10}{|c|}{ Basis Aturan (Probabilitas Kejadian } \\
Gangguan Karena Suatu Gejala) \\
\hline Gejala & GE- & GE- & GE- & GE- & GE- & GE- & GE- & GE- & GE- & GE- \\
& 001 & 002 & 003 & 004 & 005 & 006 & 007 & 008 & 009 & 010 \\
\hline GA-001 & 0,9 & 0,8 & 0,7 & 0,0 & 0,0 & 0,0 & 0,0 & 0,0 & 0,0 & 0,0 \\
\hline GA-002 & 0,0 & 0,0 & 0,0 & 0,9 & 0,8 & 0,7 & 0,0 & 0,0 & 0,0 & 0,0 \\
\hline \hline GA-003 & 0,0 & 0,0 & 0,0 & 0,0 & 0,0 & 0,9 & 0,8 & 0,7 & 0,0 & 0,0 \\
\hline GA-004 & 0,0 & 0,0 & 0,0 & 0,0 & 0,0 & 0,0 & 0,0 & 0,0 & 0,9 & 0,8 \\
\hline Gejala & GE- & GE- & GE- & GE- & GE- & GE- & GE- & GE- & GE- & GE- \\
& 011 & 012 & 013 & 014 & 015 & 016 & 017 & 018 & 019 & 020 \\
\hline GA-005 & 0,7 & 0,0 & 0,9 & 0,8 & 0,7 & 0,0 & 0,0 & 0,0 & 0,0 & 0,9 \\
\hline GA-006 & 0,0 & 0,0 & 0,0 & 0,0 & 0,0 & 0,9 & 0,8 & 0,7 & 0,0 & 0,0 \\
\hline GA-007 & 0,0 & 0,0 & 0,0 & 0,0 & 0,0 & 0,0 & 0,0 & 0,0 & 0,9 & 0,8 \\
\hline Gejala & GE- & GE- & GE- & GE- & GE- & GE- & GE- & GE- & GE- & GE- \\
& 021 & 022 & 023 & 024 & 025 & 026 & 027 & 028 & 029 & 030 \\
\hline GA-008 & 0,7 & 0,9 & 0,8 & 0,7 & 0, & 0,0 & 0,0 & 0,0 & 0,0 & 0,0 \\
\hline GA-009 & 0,0 & 0,0 & 0,0 & 0,0 & 0,9 & 0,8 & 0,7 & 0,0 & 0,0 & 0,0 \\
\hline GA-010 & 0,0 & 0,0 & 0,0 & 0,0 & 0,0 & 0,0 & 0,0 & 0,9 & 0,8 & 0,7 \\
\hline
\end{tabular}

4) Perhitungan atau diagnose
Tabel 5: Gejala Pilihan

\begin{tabular}{|c|l|}
\hline Kode Gejala & \multicolumn{1}{|c|}{ Nama Gejala } \\
\hline GE-001 & Mual dan muntah \\
\hline GE-002 & Mual pada pagi hari \\
\hline GE-003 & Mudah merasa lelah \\
\hline
\end{tabular}

Rumus untuk menghitung hasil diagnosa dapat mengguan rumus bayes sebagai berikut :

a. Perkalian

Perkalian = Perkalian Bobot Aturan Setiap Gangguan / Bobot Gangguan

b. Hasil

Hasil = Hasil Perkalian Setiap Gangguan / Total

$P(H k \mid E)=\frac{P(E \mid H k) P(H k)}{\sum_{k=1}^{H} P(E \mid H k) P(H k)}$

Berdasarkan data gangguan dan gejala diatas maka, kita dapat melakukan perhitungan sebagai berikut:

Mencari probabilitas setiap gejala:

1. $\mathrm{P}(\mathrm{E} \mid \mathrm{H} 1) \mathrm{P}(\mathrm{H} 1)=(0,9 \times 0,8 \times 0,7) \times 0,9=0,4536$

2. $\mathrm{P}(\mathrm{E} \mid \mathrm{H} 2) \mathrm{P}(\mathrm{H} 2)=(0,9 \times 0,8 \times 0,7) \times 0,9=0,4536$

3. $\mathrm{P}(\mathrm{E} \mid \mathrm{H} 3) \mathrm{P}(\mathrm{H} 3)=(0,9 \times 0,8 \times 0,7) \times 0,8=0,4032$

4. $\mathrm{P}(\mathrm{E} \mid \mathrm{H} 4) \mathrm{P}(\mathrm{H} 4)=(0,9 \times 0,8 \times 0,7) \times 0,8=0,4032$

5. $\mathrm{P}(\mathrm{E} \mid \mathrm{H} 5) \mathrm{P}(\mathrm{H} 5)=(0,9 \times 0,8 \times 0,7) \times 0,7=0,3528$

6. $\mathrm{P}(\mathrm{E} \mid \mathrm{H} 6) \mathrm{P}(\mathrm{H} 6)=(0,9 \times 0,8 \times 0,7) \times 0,7=0,3528$

7. $\mathrm{P}(\mathrm{E} \mid \mathrm{H} 7) \mathrm{P}(\mathrm{H} 7)=(0,9 \times 0,8 \times 0,7) \times 0,6=0,43024$

8. $\mathrm{P}(\mathrm{E} \mid \mathrm{H} 8) \mathrm{P}(\mathrm{H} 8)=(0,9 \times 0,8 \times 0,7) \times 0,6=0,43024$

9. $\mathrm{P}(\mathrm{E} \mid \mathrm{H} 9) \mathrm{P}(\mathrm{H} 9)=(0,9 \times 0,8 \times 0,7) \times 0,5=0,252$

10. $\mathrm{P}(\mathrm{E} \mid \mathrm{H} 10) \mathrm{P}(\mathrm{H} 10)=(0,9 \times 0,8 \times 0,7) \times 0,5=0,252$

Mencari jumlah total probabilitas:

$$
\begin{gathered}
\sum_{k=1}^{H} \dot{P}(E \mid H k) P^{-}(H k)=0,4536+0,4536+0,4032+0,4032+0,3528+0,3528 \\
+0,3024+0,3024+0,252+0,252=3,528
\end{gathered}
$$

Maka hasil dari masing - masing probabilitas adalah :

$$
\begin{aligned}
& \text { 1. } P(H 1 \mid E)=\frac{P(E \mid H \overline{1}) P(H 1)}{\sum_{k=1}^{H} P(E \mid H 1) P(H 1)}=\frac{0,4536}{3.528}=0,1285 \\
& \text { 2. } P(H 2 \mid E)=\frac{P(E \mid H 2) P(H 2)}{\sum_{k=2}^{H} P(E \mid H 1) P(H 2)}=\frac{0,4536}{3.528}=0,1285 \\
& \text { 3. } P(H 3 \mid E)=\frac{P(E \mid H 3) P(H 3)}{\sum_{k=8}^{H} P(E \mid H 3) P(H 3)}=\frac{0,4032}{3.528}=0,1142 \\
& \text { 4. } P(H 4 \mid E)=\frac{P(E \mid H 4) P(H 4)}{\sum_{k=4}^{H} P(E \mid H 4) P(H 4)}=\frac{0,4032}{3.528}=0,1142 \\
& \text { 5. } \mathrm{P}(H 5 \mid E)=\frac{P(E \mid H 5) P(H 5)}{\sum_{k=5}^{H} P(E \mid H 5) P(H 5)}=\frac{0,3528}{3.528}=0,1 \\
& \text { 6. } P(H 6 \mid E)=\frac{P(E \mid H 6) P(H 6)}{\sum_{k=6}^{H} P(E \mid H 6) P(H 6)}=\frac{0,3528}{3.528}=0,1 \\
& \text { 7. } P(H 7 \mid E)=\frac{P(E \mid H 7) P(H 7)}{\sum_{k=7}^{H} P(E \mid H 7) P(H 7)}=\frac{0,3024}{3.528}=0,885 \\
& \text { 8. } P(H 8 \mid E)=\frac{P(E \mid H 8) P(H 8)}{\sum_{k=8}^{H} P(E \mid H 8) P(H 8)}=\frac{0,3024}{3.528}=0,885 \\
& \text { 9. } P(H 9 \mid E)=\frac{P(E \mid H 9) P(H 9)}{\sum_{k=9}^{H} P(E \mid H 9) P(H 9)}=\frac{0,252}{3.528}=0,071 \\
& \text { 10. } P(H 10 \mid E)=\frac{P(E \mid H 10) P(H 10)}{\sum_{k=10}^{H} P(E \mid H 10) P(H 10)}=\frac{0,252}{3.528}=0,071
\end{aligned}
$$




\begin{tabular}{|c|c|c|c|c|c|}
\hline \multicolumn{6}{|c|}{ Perhitungan } \\
\hline $\begin{array}{c}\text { Kode } \\
\text { Gangguan }\end{array}$ & $\begin{array}{l}\text { Bobot } \\
\mathrm{P}(\mathrm{Hl})\end{array}$ & $\begin{array}{l}\text { Kode } \\
\text { Gejala }\end{array}$ & $\begin{array}{l}\text { Bobot } \\
\text { Aturan } \\
\mathbf{P}(\mathrm{E} \mid \mathrm{Hk})\end{array}$ & Perlalian & $\begin{array}{c}\text { Hasil } \\
\mathrm{P}(\mathrm{H} \mid \mathrm{E})\end{array}$ \\
\hline \multirow[t]{3}{*}{ GA-001 } & \multirow[t]{3}{*}{0,9} & GE-001 & 0,9 & \multirow[t]{3}{*}{0,4536} & \multirow[t]{3}{*}{0,1285} \\
\hline & & GE-002 & 0,8 & & \\
\hline & & GE-003 & 0,7 & & \\
\hline \multirow[t]{3}{*}{ GA-002 } & \multirow[t]{3}{*}{0,9} & GE-004 & 0,9 & \multirow[t]{3}{*}{0,4536} & \multirow[t]{3}{*}{0,1285} \\
\hline & & GE-005 & 0,8 & & \\
\hline & & GE-006 & 0,7 & & \\
\hline \multirow[t]{3}{*}{ GA-003 } & \multirow[t]{3}{*}{0,9} & GE-007 & 0,9 & \multirow[t]{3}{*}{0,4032} & \multirow[t]{3}{*}{0,1142} \\
\hline & & GE-008 & 0,8 & & \\
\hline & & GE-009 & 0,7 & & \\
\hline \multirow{3}{*}{ GA-004 } & \multirow[t]{3}{*}{0,9} & GE-010 & 0,9 & \multirow[t]{3}{*}{0,4032} & \multirow{3}{*}{0,1142} \\
\hline & & GE-011 & 0,8 & & \\
\hline & & GE-012 & 0,7 & & \\
\hline \multirow[t]{3}{*}{ GA-005 } & \multirow[t]{3}{*}{0,9} & GE-013 & 0,9 & \multirow[t]{3}{*}{0,3528} & \multirow[t]{3}{*}{0,1} \\
\hline & & GE-014 & 0,8 & & \\
\hline & & GE-015 & 0,7 & & \\
\hline \multirow[t]{3}{*}{ GA-006 } & \multirow[t]{3}{*}{0,9} & GE-016 & 0,9 & \multirow[t]{3}{*}{0,3528} & \multirow[t]{3}{*}{0,1} \\
\hline & & GE-017 & 0,8 & & \\
\hline & & GE-018 & 0,7 & & \\
\hline \multirow[t]{3}{*}{ GA-007 } & \multirow[t]{3}{*}{0,9} & GE-019 & 0,9 & \multirow[t]{3}{*}{0,3024} & \multirow[t]{3}{*}{0,885} \\
\hline & & GE-020 & 0,8 & & \\
\hline & & GE-021 & 0,7 & & \\
\hline \multirow[t]{3}{*}{ GA-008 } & 0,9 & GE -022 & 0,9 & 0,3024 & 0,885 \\
\hline & & GE-023 & 0,8 & & \\
\hline & & GE-024 & 0,7 & & \\
\hline GA-009 & 0,9 & GE-025 & 0,9 & 0,252 & 0,071 \\
\hline & & GE- 026 & 0,8 & & \\
\hline & & GE- 027 & 0,7 & & \\
\hline GA-010 & 0,9 & GE-028 & 0,9 & 0,252 & 0,071 \\
\hline & & GE-029 & 0,8 & & \\
\hline & & GE- 030 & 0,7 & & \\
\hline $\mathrm{T}$ & $1 \Sigma^{\prime \prime} P($ & $H k) P(H$ & & 3,528 & \\
\hline
\end{tabular}

Hasil analisa dari ganguan-gangguan diatas menunjukan bahwa nilai tertinggi adalah pada kode gangguan GA-001 atau Morning Sickness

B. Diagram Konteks

Diagram Konteks merupakan alat untuk struktur analisis. Pendekatan struktur ini untuk menggambarkan sistem secara garis besar atau secara keseluruhan. Pada diagram konteks ini dapat kita mengetahui sumber informasi yang dibutuhkan dan tujuan informasi yang dihasilkan dari sistem yang dibuat. Untuk lebih jelasnya bisa dilihat pada gambar berikut ini:

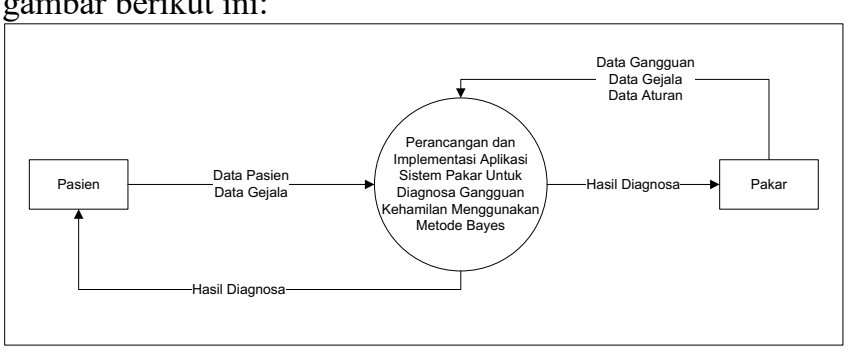

Gambar 1. Diagram Konteks

\section{Entity Relationship Diagram}

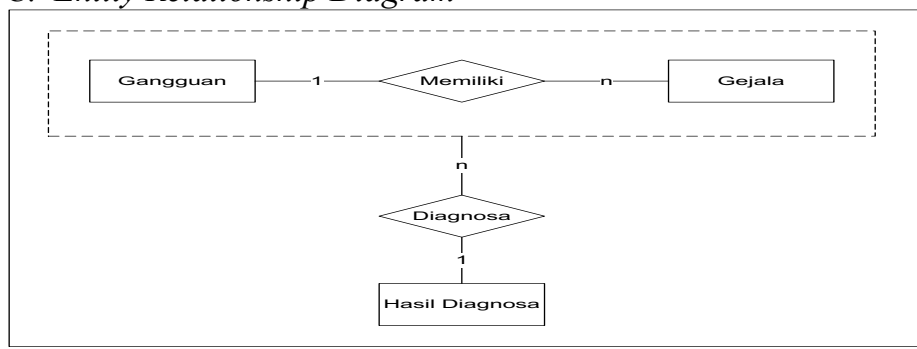

Gambar 2. Entity Relationship Diagram

D. Data Flow Diagram

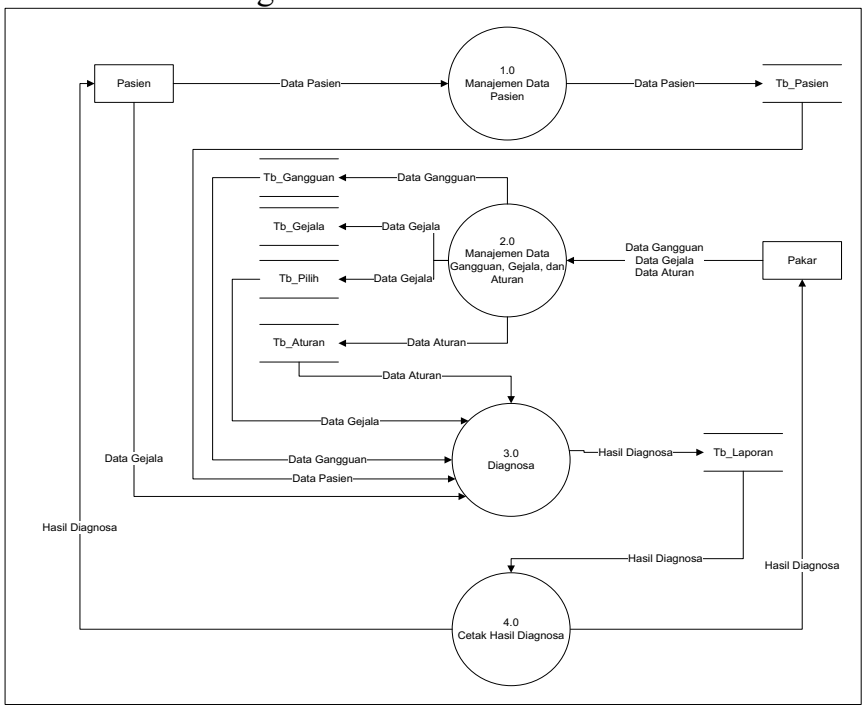

Gambar 3. Data Flow Diagram

E. Interface Aplikasi

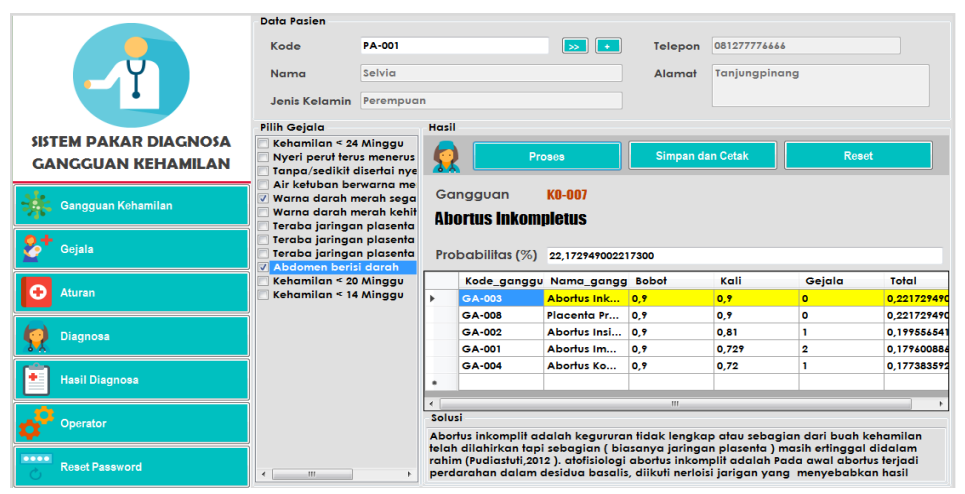

Gambar 4. Tampilan Aplikasi

\section{IV.KESIMPULAN}

Sistem Pakar yang dibuat dapat membantu mendiagnosa gangguan yang terjadi pada masa kehamilan yang diakibatkan oleh gejala-gejala yang muncul sehingga mempermudah dalam memberikan penanganan yang cepat dan tepat. Sistem pakar ini dirancang beserta keluarannya berupa solusi untuk penanganan jenis gangguan dan memberikan penjelasan 
penyebab gangguan kehamilan. Dengan komputer sebagai sarana pendukung aplikasi untuk mendiagnosa gangguan pada kehamilan dengan pendekatan sistem pakar serta database pengetahuan mengenai hal-hal yang berhubungan dengan jenis gangguan kehamilan.

\section{UCAPAN TERIMA KASIH}

Dalam kesempatan ini penulis ingin mengucapkan terimakasih kepada semua pihak yang telah membantu dalam penyelesaian penelitian ini khususnya kepada dosen pembimbing dan seluruh civitas akademika kampus STTI Tanjungpinang.

\section{REFERENSI}

[1] A.S Rosa, dan Shalahuddin M, Rekayasa Perangkat Lunak Terstruktur dan Berorientasi Objek, Informatika, 2013, Bandung.

[2] Aspuah Siti, Kumpulan Kuesioner dan Instrumen Penelitian Kesehatan, 2013, Yogyakarta.

[3] Gavinov Tinarbudi Ivan \& Soemantri Nervan J.F, Sistem Informasi Kesehatan, Nuha Medika, 2016, Yogyakarta.

[4] Hartati dan Iswanti, Sistem Pakar \& Pengembangannya, 2011, Yogyakarta

[5] Hartono Bambang, Sistem Informasi Manajemen Berbasis Komputer, PT. Rineka Cipta, 2013, Jakarta.

[6] Maimunah, Henderi dan Andrian, Randy, Desain aplikasi E-Learning Sebagai Media Pembelajaran Artificial Informatics", Journal CCIT Vol-4 No.3 - Mei 2011.

[7] Mulyanto Sutojo dan Suhartono, Kecerdasan Buatan, Universitas Dian Nuswantoro, 2011, Semarang.

[8] Purwoastuti Endang dan Walyani Siwi Elisabeth, Panduan Materi Kesehatan Reproduksi dan Keluarga Berencana, Pustaka Baru Press, 2015, Yogyakarta.

[9] Salman Rusmalia B dan Polim Adrianus Arie, 30 Perubahan Tubuh Selama Hamil Pustaka Kemang, 2016, Jakarta.

[10] Sholihah Lutfaitus, Panduan Lengkap Hamil Sehat, DIVA Press, 2016, Yogyakarta.

[11] Sutabri Tata, Konsep Sistem Informasi, CV. Andi Offset, 2012, Yogyakarta.

[12] Taufiq Rohmat, Sistem Informasi Manajemen, Graha Ilmu, 2013, Yogyakarta.

[13] Agustina, Sistem Pakar Mendiagnosa Penyakit Kista Ovarium dengan menggunakan Metode Bayes, 2014, Tersedia di.html [diunduh : 16 Desember 2017] 